\title{
Oral Erythema Multiforme: Laboratory findings in monitoring Herpes Simplex Virus involvement (A case report)
}

\author{
Maria Leny Raiyon*, Gus Permana Subita** \\ *Resident Department of Oral Medicine Faculty of Dentistry Universitas Indonesia \\ ${ }^{* *}$ Department of Oral Medicine Faculty of Dentistry Universitas Indonesia
}

\section{ABSTRACT}

Erythema Multiforme is polymorphous recurrent eruptions on the skin and oral mucosa. This case is describing a progression of a case of Erythema Multiforme in oral mucosa of a 33 year old man suggesting of herpes viral involvement. In the absence of identified inducing drugs, past medical history of clinical manifestation on Herpes Simplex Viral (HSV) but positive serum antibody against HSV-1 is suggesting of Herpes Associated Erythema Multiforme. This was became the basis of the patient management. Several episodes of recurrences and relapses occurred during our treatment period in oral isolated sites which were later progressed with skin eruption of bullae. The later clinical presentation challenges the on going working diagnosis. It was also necessitate a skin biopsy to rule out other possibility of bullous lesion diseases. The latter blood test showed seroconverted of HSV-2 antibody accompanying previous detected HSV-1 antibody. Both biopsy and peripheral blood sera test consistent with Herpes Simplex Virus involvement. Patient is on a scheduled antiviral prophylaxis. This case showed that Herpes Associated Erythema Multiforme (HAEM) does presented initially as an isolated oral lesions and serological test could be used to monitor seroconverting of HSV.

Key words: Erythema Multiforme, HAEM, HSV, anti-HSV imunoglobulin

\section{INTRODUCTION}

Erythema Multiforme (EM) is initially described by a doctor, Ferdinan von Hebra, in his report in 1866. Also known as Erythema Multiforme von Hebra, this abnormality is described as a relatively rare abnormality characterized by the rapid appearance of target lesion on the skin starting from several lesions to hundreds of lesions. ${ }^{1}$ The lesion can happen episodically each month or randomly recurrent.

Erythema Multiforme have been discussed in its relationship with reactions induced by drug use and a skin presentation is usually reported. Besides being triggered by the use of several certain drugs, EM is also reported as being triggered by the use of flavor agent in food, certain chemicals in surrounding environment and also infection agents. ${ }^{2,3}$ Infection agents that have been reported are virus, bacteria and fungi. ${ }^{3}$ Even though it has been suggestions on the involvement of Herpes Simplex Virus (HSV) in triggering EM since the $19^{\text {th }}$ century, the scientific evidence on the virus involvement was not presented until 
recently. ${ }^{4-14}$

We report an EM case that involves oral and skin mucosa. The infection caused by HSV-1 was detected in seroimmunological tests and along the course of the case, antibody against HSV-2 was also detected. The importance of detecting the involvement of HSV in EM case will be discussed further.

\section{CASE REPORT}

A 33 year old male patient visited the Oral Disease Department of Oral and Dental Clinic, Dr. Cipto Mangunkusumo Central Hospital several times with recurrent serosanguinous crust on the lips that become harden with easily bleeding base. There were multiple irregular erythematous lesions in the intraoral mucosa with ulcerations seen in several locations. The lesions were easily bleeding and pain was felt when opening mouth (Fig. 1-4). Oral hygiene seemed poor. From the patient's history it was revealed that this condition had been experience 6 month ago before he first came to the clinic and patient had sought for treatment to several doctors. During the 5 months before he came to the clinic, patient kept using the antiseptic prescribed by his previous doctor. The patient realized that there was a tendency to experience aphthous before but it was never this severe. A Herpes zooster history on the right back was found but it was already treated in 2001. The patient's observation stated that in the past the aphthous only involved lips but it now involves the tongue. A week before the first lesion appeared, patient experienced fever and flu-like symptoms followed by small wounds on the upper lip that became bigger along the time. Work-related stressed was not denied. The general health impression of the patient was good and patient was not under certain medications except for multivitamin supplement. Patient denied the used of over the counter drugs and herbs, smoking and drinking habit.

In the course of this case the patient experienced up to 4 episodes of erythema in a year with different intervals and not much variations of the mucosa involvement, i.e. ulcerative erytemathous lower lip and intra oral. In the $4^{\text {th }}$ episode of the disease after the first visit, bulosa lesion on his upper chest and erythema on his right fingers were also found together with the oral lesions. A joint treatment was then performed with the dermatology department by doing biopsy of the area.

Microscopic tissue section seemed to be shrinking, which probably due to the poor fixation process. The histology of the chest and right finger skin biopsy shows chronic inflammation around dilated vessels. In chest skin section, achantholysis of the epidermis surface with gaps around base membrane was seen. Necrosis was seen with bulous filled with mixed inflammation cells and fibrin. Overall, the histological appearance of the two skin specimens was consistent with the appearance of Erythema Multiforme.

Laboratory tests on the blood were performed during the first visit and twice during the recurrent period (Tab. 1). Herpes simplex

Table 1. The result of blood count test during recurrent period.

\begin{tabular}{|c|c|c|c|}
\hline & $\begin{array}{c}16 \text { Des } \\
2006\end{array}$ & $\begin{array}{c}8 \text { Agust } \\
2006\end{array}$ & $\begin{array}{l}10 k t \\
2007\end{array}$ \\
\hline LED & 31 & 25 & 30 \\
\hline Haemoglobin & 10.8 & 10.7 & 10.7 \\
\hline Haematocrit & 34 & 35.1 & 33 \\
\hline Erithrocyt & 5.2 & 5.17 & 4.89 \\
\hline MCV & TD & 67.9 & 67 \\
\hline $\mathrm{MCH}$ & TD & 20.7 & 22 \\
\hline $\mathrm{MCHC}$ & TD & 30.5 & 33 \\
\hline Thrombocyt & 274 & 329 & 274 \\
\hline Leucocyt & 5.4 & 8.0 & 12.1 \\
\hline \multicolumn{4}{|c|}{ Leucocyte blood count } \\
\hline Eosynophil & 3 & 1.0 & 0 \\
\hline Basophil & 0 & 0 & 0 \\
\hline Neutrophil & 45 & 54.0 & 82 \\
\hline Lymphocyt & 43 & 38 & 9 \\
\hline Monocyt & 9 & 7.0 & 9 \\
\hline Glucosa & 92 & TD & 130 \\
\hline Urine reduction & TD & TD & TD \\
\hline Ureum & TD & TD & 30 \\
\hline Creatinin & TD & TD & 0.90 \\
\hline Alcali Phosphatase & TD & TD & 56 \\
\hline SGOT & TD & TD & 15 \\
\hline SGPT & TD & TD & 8 \\
\hline Malaria & TD & TD & $(-)$ \\
\hline Anti HSV I IgG & $(+) 3.3$ & TD & (+) 3.01 \\
\hline Anti HSV I IgM & $(-)$ & TD & $(-)$ \\
\hline Anti HSV II IgG & $(-)$ & TD & (+) 1.21 \\
\hline Anti HSV II IgM & $(-)$ & TD & $(-)$ \\
\hline Anti HIV & TD & TD & $(-)$ \\
\hline
\end{tabular}

ND: Not done

Bold: serum-immunological test 


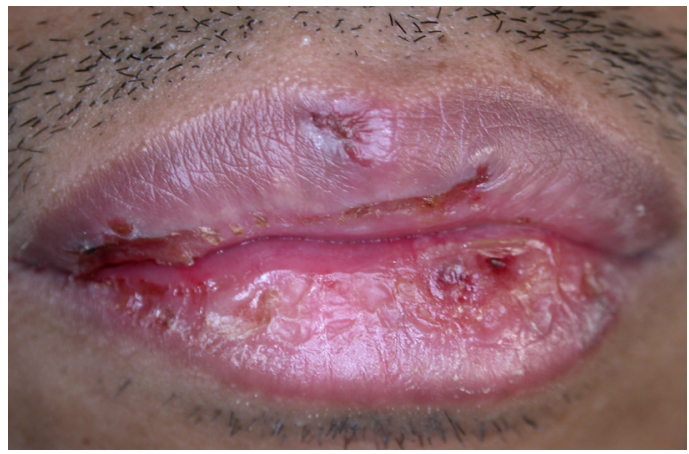

Figure 1. Extra oral lesion.

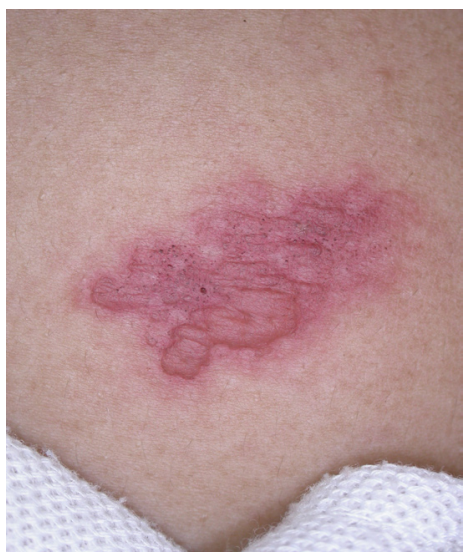

Figure 3. Bullae in patient's chest skin.

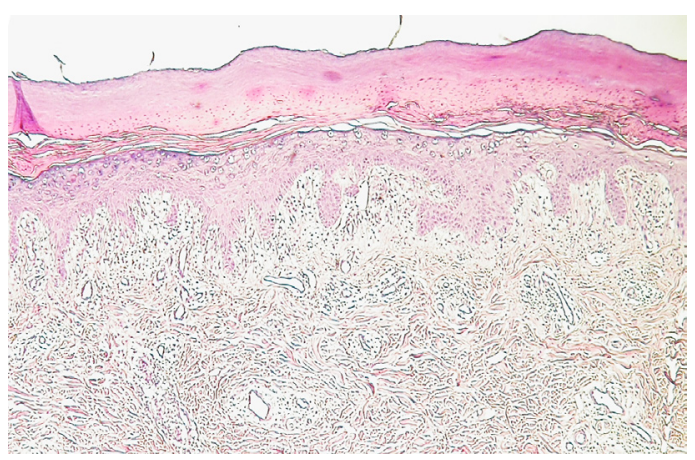

Figure 5. Histological appearance in finger biopsy with atypical erythematous lessions (40x).

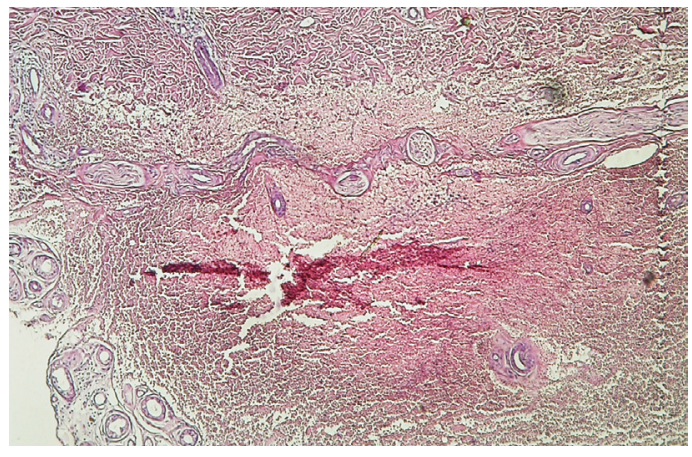

Figure 6. Cutaneous layer with necrotic focus and chronic inflammation cells invasions (40x).

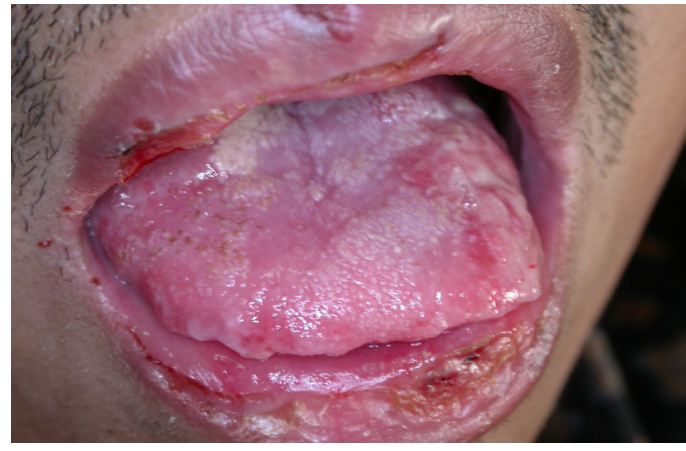

Figure 2. Intra oral lesion.

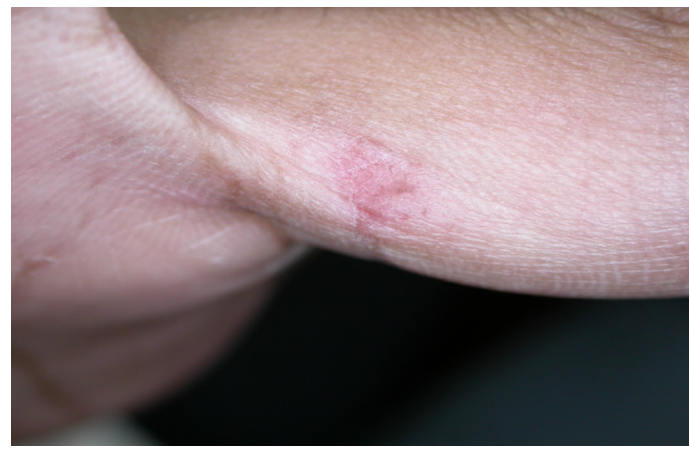

Figure 4. Atypical erythematous lessions in finger.

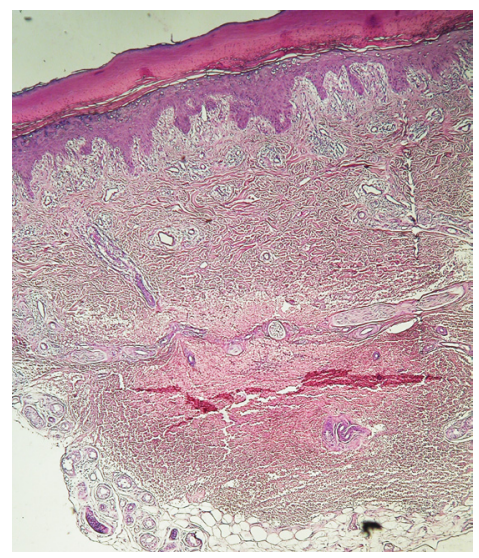

Figure 7. Epithelial and cutaneous tissue in section thickness $(40 x)$.

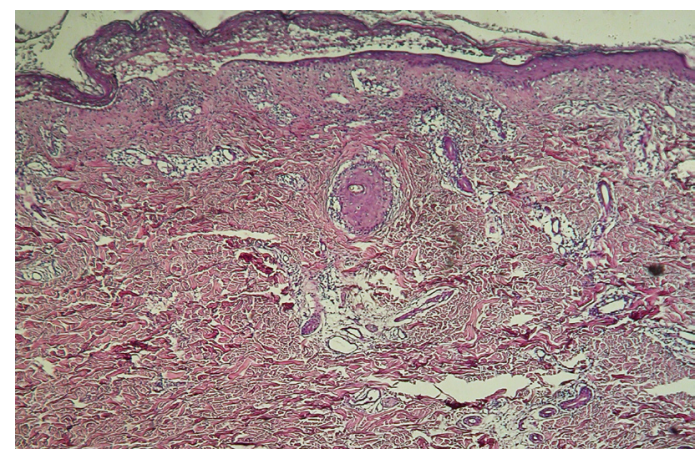

Figure 8. Histological appearance in a bullae of chest skin (40x). 
virus fragment was detected, which was shown by increased antigen towards immunoglobulin G HSV1 while anti-HSV- 2 was detected in the $10^{\text {th }}$ month after the first serum immunological tests.

Patient management was emphasized on the symptomatic condition. Supportive treatment that includes soft diet and analgesic was also recommended and high protein milk and mouthwash with anesthetic effect were also provided. Corticosteroid therapy in the initial phase of the treatment was given in topical manner (prednison mixture). However, along the course of the case, the corticosteroid was given systemically through oral preparation, especially when the erythema already involved broad mucosa and bulous was found on the skin. Antiviral prophylaxis (acyclovir) to target HSV-1 and -2 was also given and up to the reporting time the prophylaxis is still given.

\section{DISCUSSION}

Challenges in diagnosing a patient suspected of EM include various clinical type of EM. The EM clinical appearance may include multiple papules and vesicles starting by erythematous macules, superficial irregular erosion, which is the area caused by vesicular rupture with yellow fibrinous pseudomembrane layer, up to broad shallow irregular multiple ulcerations surrounded by erythematous margin and are covered by epithelial

Table 2. Erithema Multiforme classification and clinical appearance and another related disorders.

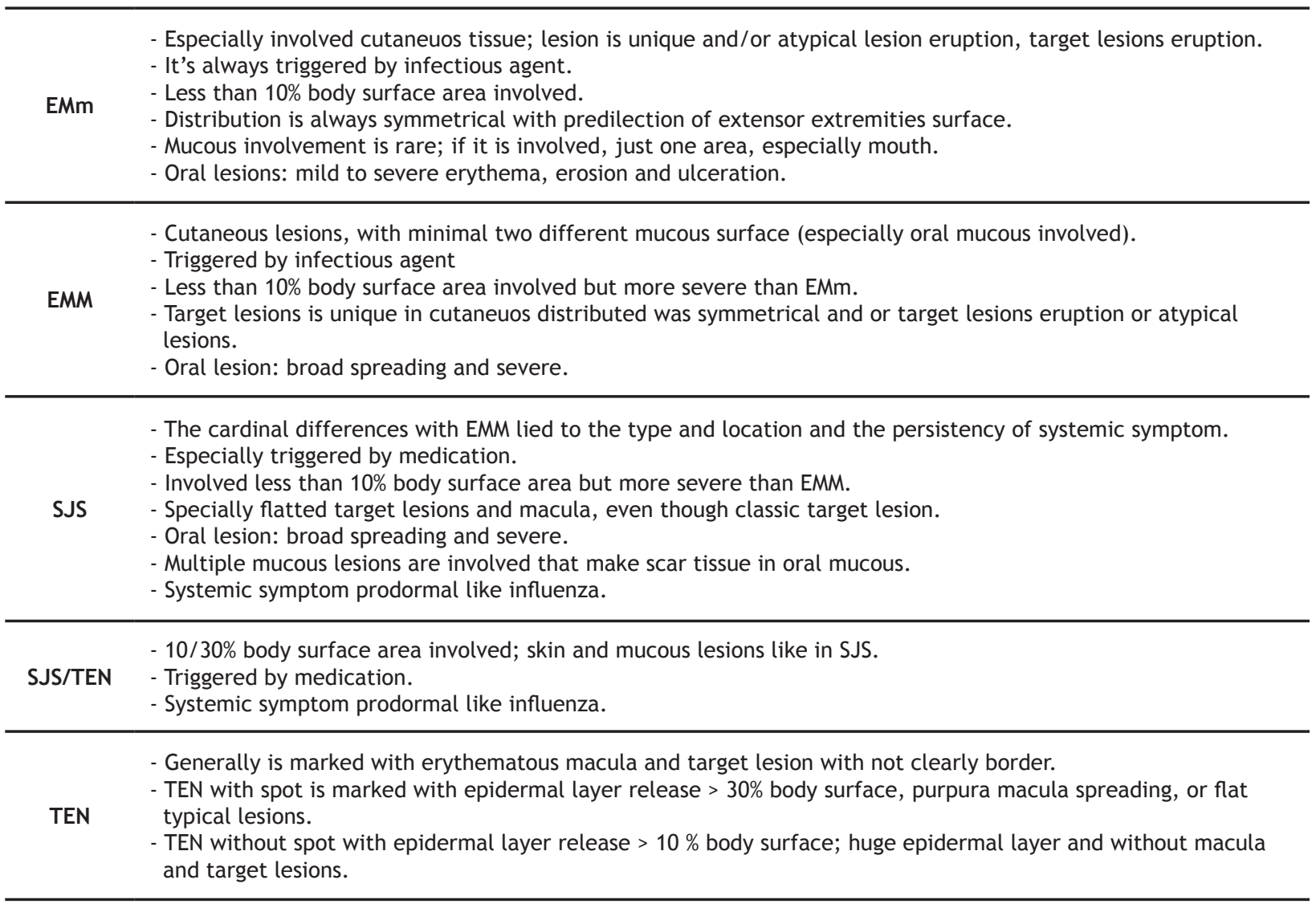

Note: EM: Erithema Multiforme, EMm: Erythema Multiforme minor, EMM: Erythema Multiforme mayor, SJS: Steven Johnsosn Syndrome, TEN Texic Epidermal Necrolysis.

Lesion Description:

Typical target: Individual lesions with $<3 \mathrm{~cm}$ diameter, round shape, clearly border and has at least 3 different zone inside lesion. It is two concentris ring that's surrounding a center with disc shape. One of the ring is oedema area, it can be palpated, and the colour more pale in accordance with center of the lesion.

Eruption atypical target: round shape, oedema, can be palpated liked typical lesions but just consist of 2 zona with or without clearly border.

Flat atypical target: Unique round lesions in EM but just have two zone with/without clearly border and can't be palpated, except the lesions with ulceration in the middle.

Macula with or without ulceration: not palpated, erythematous, or purpuric macula with irreguler size and shape and often continued. Ulceration always happen in the part of macula lesions. 
desquamation in the form of white plaque. The locations usually affected are lingual mucosa, buccal mucosa, and/or labial mucosa and, rarely, oral base mucosa, palatum mucosa and gingival mucosa. ${ }^{15}$ However, a diagnosis is possible through careful observation on the clinical appearance of the lesion, disease history and histological appearance. ${ }^{16}$ The laboratory assays available today are supportive in nature to help differentiating EM lesion using delayed hypersensitive reaction to HSV particle and identifying drug induction cause.

Just like what is seen in this patient, EM is usually experienced by young adults with sharp increase in 20-40 year old group with male more dominant than female. Usually, the condition is recurrent with $70 \%$ of cases are started with herpes infection. ${ }^{8,17,18}$ In this case, the initial work diagnosis is made based on the clinical appearance of mucosa membrane involvement in the form of erythematous area with eroded area that may involve a quite extended area especially in tongue dorsum up to the form of ulceration.

The erosive and ulcerative condition is considered a sequel of cytotoxic immunological attack in keratinocytes that have non-self antigen expression that creates necrosis in the epithelial cells. ${ }^{19}$ These characteristics are similar to a broader erosive condition of Steven Johnson Syndrome (SJS) and Toxic Epidermal Necrolysis (TEN). EM, SJS and TEM generally share similar clinical appearance with unique or less unique cutaneous target lesion variances and satellite cells or epithelial necrosis area with different severity expression (Tab 2). ${ }^{3}$

In its development, the case started as minor EM lesions that only involved oral mucosa with $<10 \%$ epithelial surface involvement of the body. However, during the recurrent episodes, i.e. patient's $4^{\text {th }}$ visit, it also involved cutaneous tissue (chest and finger skin) making the lesions in this patient matches the classification of mayor EM suggested by Al - Johani (see Tab. 2).

A lot of clinicians considered EM, Steven Johnson Syndrome (SJS) and Toxic Epidermal Necrolysis (TEN) as progressive diseases with EM as the mildest expression, followed by SJS and TEN as the most severe one. However, the thought has been shifted. Now, it is believed that the three conditions area separate conditions. ${ }^{20}$ While in SJS and TEN it was reported that the etiological agent is drug that is seen in $50 \%$ and $85-90 \%$ of the cases $^{21}$, respectively, EM is often found related to infection agents with HSV found in $70-80 \%$ of the cases. ${ }^{22}$ In a case report it was found that $71 \%$ of EMm/AMM lesions are preceded by HSV infection. ${ }^{23}$ Many patients who experienced single episode of $E M$ and recurrent $E M$ episode report a viral infection history several days to 2 weeks before EM lesions were observed. ${ }^{24-27}$

In the last 20 years, more scientific findings strengthen the role of HSV as a causal factor of Erythema Multiforme eruption. ${ }^{1}$ It is even believed that the EM patients considered as idiopathic in the past are actually included in the group that is triggered by HSV. HSV is identified as a common infection agent with a seroprevalence of up to $90 \%$ has been reported for certain population. ${ }^{28}$ The HSV infection is also known as the cause of viral enchepalitis and blindness but it is estimated that only $2 \%$ of the seropositive population who experience target lesion eruption.

Brice et al. ${ }^{12}$ initially demonstrated the presence of HSV DNA circulation in peripheral mononuclear blood cells (PMBC) in 4 of 5 patients with $E M$ skin lesion that had been observed. At that moment, it was still debatable whether all HSV genomes were circulated in the peripheral blood or only some fragments were found. Using PCR amplification, Brice et al. ${ }^{10}$ use three primers from different regions to detect HSV DNA circulated and concluded that it was indeed the whole HVS genome was circulated although they failed to culture it. Ten years later, using a more sophisticated technology, Aurelian et al. ${ }^{5}$ was able to amplify two ends of HSV genome, ICP27 gene and Pol (the viral DNA polymerase gene). Pol is discovered in EM patients with no ICP27. ${ }^{5}$ This finding was interpreted by Aurelian et al. as the evidence that it is HSV DNA fragment that circulates, not the whole genome. Further, Aurelian et al. ${ }^{5}$ was able to observe that $\mathrm{CD} 34+$ cells are initially infected by HSV. However, the cells cannot be made as the place for HSV replication and during the observation it is revealed that the cells become HSV free in 7 days after being cultured. In the previous observation ${ }^{29}$, this group has found persistent HSV up to 3 months on the skin that previously experienced lesion. Nevertheless, it was postulated by this group that the weakness experienced by the herpes-associated EM is that 
the immune system of these patients cannot clean the viral particles. ${ }^{29}$

Because of this frequently observed relationship, the term Herpes Associated Erythema Multiforme (HAEM) is used and is getting more and more frequently used in literatures. Aurelian et al. ${ }^{6}$ has stated several arguments related to HAEM diagnosis. The group has observed the involvement of HSV in EM during these 2 decades and has presented molecular and immunological data on HSV role as the etiological factors triggering autoimmune component reaction. The discussion is far beyond this writing (a specific discussion can be found in the review). The clinical findings that strengthen the hipothesis of HSV involvement are: First, HAEM almost always follow HSV lesion and never the other way around; second, there are viral antigens on the skin that cause HAEM.9,29 In HAEM lesion, HSV DNA fragment is found where previously, due to the limitation of detecting technique, thought that all viral genome circulates in the blood of HAEM patients. There are quite significant variations in the detection number reported, which is related in part to the criteria selection of the observed cases. The selection of the cases reported may possibly include subject that clinically related to HSV infection. The third is that prolonged prophylaxis with acyclovir is proven to prevent and decrease the prevalence of recurrence of HSV and HAEM lesion. ${ }^{6}$

Besides external factors, a possibility that there is a genetic predisposing factor for EM occurrence is also known. The detection of HLAB15 (B62), B35, A33, DR53, DQB1*0301 and DQw3 allele expression relates to HSV recurrent lesions. DQB1 0302 in mucosal membrane tends to be mild while DQB1*0402 in the severe mucosal membrane involvement strengthen the hypothesis of a genetic tendency. ${ }^{23,30-32}$ The involvement of genetic factors is also a finding that can be used to answer the questions why the majority population that has been infected by HSV does not show sensitivity reaction towards HSV. ${ }^{11,33}$

Based on the consideration of HSV involvement in EM pathogenesis, HSV particles/fragment assay in EM patient's blood becomes the foundation to confirm HAEM diagnosis. It has been estimated for a long time that the HAEM presentation that is similar to delayed type hypersensitivity reaction shows an immune response condition induced by HSV antigens. However, the involvement of specific immune reaction towards HSV is difficult to be shown because the titer and HSV specific antibody activity, phenotype distribution and CD functions are similar in HAEM and HSV. ${ }^{11,33}$

HSV fragment examination in lesion biopsy has never been a routine procedure. The test that can be performed is indirect test for the presence of HSV fragments in the blood. In this patient, it is observed that there is increased IgG anti HSV1 since the first visit during the examination. In 10 months after the first visit, a seroconversion in IgG anti -HSV-2 that was undetected in the first visit became 1.21 and the IgG anti-HSV-1 is relatively stable 3.01. Although the antigen serum test does not specifically differentiate HSV presence from shedding dormant HSV in the epithelial tissue that has been infected or from HAEM recurrent condition, until this moment ${ }^{34}$, for the clinical application, this test is still an available choice. The link of EM lesion with HSV DNA circulation episode is based on many findings that in EM patients, HSV-1 and HSV-2 DNA can be isolated and it is the seropositive HSV antigen that gives an opportunity to the clinician to be able to monitor EM patient condition before the lesions are presented clinically. Nevertheless, it makes prophylaxis or necessary approach to lessen patient's suffering during recurrent episode possible for the clinician. ${ }^{34} \mathrm{~A}$ more specific tests for HAEM such as detecting interferon-g (IFN-g) that is a specific response towards viral antigen (released by T-helper 1 ) is still in trial in research laboratory and is not available yet for routine examination. ${ }^{4,6,8}$

\section{CONCLUSION}

Approaches in erythema multiforme case should pay attention to the possibility of the viral etiology involvement during management consideration. Since HSV-1 and HSV-2 are known to play a role in inducing hypersensitivity reactions among EM patients, it is suggested to perform HSV antibody serum examinations to patients to see the immunological serum status and to support actions in HAEM management, including prophylaxis. In the future, laboratory tests to see the involvement of etiological agents will be available in more specific choices. 


\section{REFERENCES}

1. Weston W. Herpes-associated Erythema Multiforme. J Invest Dermatol 2005:124;xvxvi. [cited 2007 Feb 16] Available from: DOI: 10.1111/j.0022-202X.2005.23764.X.

2. Lozada-Nur F, Silverman S. Erythema Multiforme: clinical characteristics and natural history in 50 patients. Oral Surg 1978;46:62836.

3. Farthing P, Bagan J-V, Scully C. Mucosal diseases series: Erythema Multiforme. Oral Disease 2005;11:261-7.

4. Ono F, Sharma B, Smith C, Burnett J, Aurelian L. CD34+ cells in the peripheral blood transport Herpes Simplex virus DNA fragments to the skin of patients with Erythema Multiforme. J Invest Dermatol 2005;124:1215-24.

5. Aurelian L, Ono F, Sharma B, Smith C, Burnett J. CD34+ cells in the peripheral blood transport Herpes Simplex Virus (HSV) DNA fragments to skin of patients with Erythema Multiforme (HAEM). J Invest Dermatol 2005;124:1215-24.

6. Aurelian L, Ono F, Burnett J. Herpes Simplex virus (HSV) - Associated Erythema Multiforme (HAEM): A viral disease with an autoimmune component. [online]. [cited 2008 May 06] Dermatolog Online J 2003;9.

7. Kokuba H, Aurelian L, Burnett J. Herpes Simplex Virus associated Erythema Multiforme (HAEM) is mechanistically distinct from druginduced Erythema Multiforme: Interferon-g is expressed in HAEM lesions and tumor necrosis factor-a in drug-induced Erythema Multiforme lesions. J Invest Dermatol 1999;113:808-15.

8. Kokuba H, Imafuku S, Huang S, Aurelian L, Burnett J. Erythema Multiforme lesions are associated with expression a Herpes Simplex Virus (HSV) gene and qualitative alterations in the HSV-spesific T-cell response. $\mathrm{Br} J$ Dermatol 1998;138:952-64.

9. Imafuku S, Kokuba H, Aurelian L, Burnett J. Expression of Herpes Simplex Virus DNA fragments located in Epidermal Keratinocytes and germinative cells is associated with the development of Erythema Multiforme. J Invest Dermatol 1997;109:550-6.

10. Brice S, Leahy M, Ong L. Examination of noninvolved skin, previously involved skin and peripheral blood for Herpes Simplex Virus DNA in patients with recurrent Herpes Associated Erythema Multiforme. J Cutan Pathol 1994; 21:408-12.

11. Brice S, Stockert S, Bunker J. The Herpesspecific immune response of individuals with Herpes-associated Erythema Multiforme compared with that of individual with recurrent Herpes Labialis. Arch Dematol Res 1993;285:193-6.

12. Brice $S$, Stockert $S$, Jester J, Huff J, Weston W. Detection of Herpes Simplex Virus in the peripheral blood during Acute Recurrent Herpes Labialis. J Am Acad Dermatol 1992;26:594-8.

13. Aslanzadeh J, Helm K, Espy M, Muller S, Smith T. Detection of HSV-specific DNA in biopsy tissue of patients with Erythema Multiforme by polymerase chain reaction. $\mathrm{Br} J$ Dermatol 1992;126:19-23.

14. Brice S, Krzemien D, Weston W, Huff J. Detection of herpes simplex virus DNA in cutaneous lesions of Erythema Multiforme. J Invest Dermatol 1989;93:183-7.

15. Al-Johani K, Fedele S, Porter S. Erythema Multiforme and related disorder. Oral Surg Oral Med Oral Pathol Oral Radiol Endod 2007; 103:642-54.

16. Lozada-Nur F, Shillitoe E. Erythema Multiforme and Herpes Simplex virus. J Dent Res 1985; 64:930-1.

17. Carrozzo M, Togliatto M, Gandolfo S. Erythema Multiforme: A heterogenous pathologic phenotype. Minerva Stomatol 1999;48:217-26.

18. Schofield J, Tatnall F, Leigh I. Recurrent Erythema Multiforme: clinical features and treatment in a large series of patients. $\mathrm{Br} \mathrm{J}$ Dermatol 1993;128:542-5.

19. Ayangco L, Rogers RI. Oral manifestations of Erythema Multiforme. Dermatol Clin 2003; 21:195-205.

20. Auquier-Dunant A, Mockenhaupt M, Naldi L. Correlations between clinical patterns and causes of Erythema Multiforme Major, StevensJohnson Syndrome, and Toxic Epidermal Necrolysis: Results of an international prospective study. Arch Dermatol 2002;138: 1019-24.

21. Roujeau J, Kelly J, Naldi L. Medication use and the risk of Steven-Johnson Syndrome or Toxic Epidermal Necrolysis. N Engl J Med 1995;333:1600-8. 
22. Howland W, Golitz L, Weston W, Huff J. ErythemaMultiforme: clinical, histopathologic, and immunologic study. JADA 1984;10:438-46.

23. Schofield J, Tatnall F, Brown McCloskey J, Navarette C, Leigh I. Recurrent Erythema Multiforme: tissue typing in a large series of patients. Br J Dermatol 1994;131: 532-5.

24. Leigh I, Mowbray J, Levene G, Sutherland S. Recurrent and continuous Erythema Multiforme: A clinical and immunological study. Clin Exp Dermatol 1985;10:58-67.

25. Nesbit S, Gobetti J. Multiple recurrence of oral Erythema Multiforme after secondary Herpes Simplex: Report of case and review of literature. JADA 1986;112:348-52.

26. Huff J, Weston W. Recurrent Erythema Multiforme: Acritical review of characteristics, diagnostic criteria, and causes. Baltimore: Medicine; 1989. p. 68.

27. Farthing $P$, Maragou P, Coates M. Characteristic of the oral lesions in patients with cutaneous recurrent Erythema Multiforme. J Oral Pathol Med 1995; 24: 9-13.

28. Wheeler C. The Herpes Simplex problem. J Am
Acad Dermatol 1988;18:163-8.

29. Miura S, Smith C, Burnett J. Detection of viral DNA within skin of healed recurrent herpes simplex infection and Erythema Multiforme lesions. J Invest Dermatol 1992;98:68-72.

30. Legendre C, Russell A, Jeannet M. HLA antigens in patients with recrudescent Herpes Simplex infections. Tissue Antigens 1982;19:85-9.

31. Khalil I, Lepage Douay V, Morin L et al. HLA DQB1*0301 allele is involved in the susceptibility to Erythema Multiforme. J Invest Dermatol 1991;97:697-700.

32. Malo A, Kampgen E, Wank E. Recurrent Herpes Simplex virus-induced Erythema Multiforme: different HLA DQB1 alleles associate with severe mucous membrane versus skin attcks. Scand J Immunol 1998; 47:408-11.

33. Onishi I, Kishimoto S. Erythema Multiforme after resolution of Herpes Zoster by acyclovir. Eur J Dermatol 2002;12:370-2.

34. Gilbert S. Oral shedding of Herpes Simplex Virus I in immunocompetent persons. J Oral Pathol Med 2006;35:548-53. 